\title{
On null spatial Ps and their arguments*
}

\author{
Arhonto Terzi \\ Technological Educational Institute of Patras \\ Meg. Alexandrou 1, Koukouli, Patras, 26334, Greece \\ aterzi@teipat.gr
}

Received: April 192010

Accepted: October 52010

\begin{abstract}
This paper investigates the phenomenon of null spatial Ps, focusing primarily on Greek where these are most widely attested. It is demonstrated that only locatives (of the type that do not denote containment), as well as directional goal Ps, are able to surface without phonetic content when their nominal arguments are determinerless.

It is suggested that the presence of null spatial Ps is contingent on nominals of special status, namely, on elements which, although similar in phonetic content to common nouns, are in fact closer to adverbials. In particular, it is suggested that the arguments of silent spatial Ps either instantiate or modify the silent noun PLACE. The latter raises to the specifier position the associated spatial $\mathrm{P}$, with the consequence that $\mathrm{P}$ may appear without phonetic content - by virtue of the fact that its lexicalization requirements may (also) be satisfied in this manner.
\end{abstract}

Key words: null spatial Ps, place nouns, PLACE.

\section{Table of Contents \\ 1. Introduction 4. Nous that may appear with null Ps \\ 2. The facts 5. An explanation for null spatial Ps \\ 3. Types of null Ps References}

\section{Introduction}

This paper investigates a phenomenon manifested extensively in Greek, and to a lesser extent in a few other languages, according to which the arguments of a locative or directional P surface bare and the associated spatial $\mathrm{P}$ is missing. The phenomenon is mentioned in passing in Longobardi (2001) with reference to the Veneto dialects, and is studied in detail by Ioannidou and den Dikken (2006) with respect

* Research on this topic was initiated in the Fall semester of 2008-2009, while I was visiting New York University during my sabbatical. For comments on an earlier written version of the paper I would like to thank Andrea Cattaneo and Marika Lekakou. 
to Greek. Here I expand the empirical coverage of the latter study by investigating more closely the properties of both, the spatial Ps and the nominals that participate in the construction, while taking into consideration current theoretical developments in both syntactic domains. Moreover, I bring into the discussion recent studies of the phenomenon in other languages, in particular, English (Collins 2007) and Northern Italian Dialects (Cattaneo 2009). Consequently, the paper should be conceived as an overview of what has been said on the topic so far, while at the same time being concerned with the contribution of the related discussion to the broader issue of the syntactic structure of spatial Ps.

In the end, I sketch an account of null spatial Ps according to which their occurrence is closely related to both properties of their nominal arguments, and lexicalization requirements that pertain to the structure of Ps per se. It is argued that the nominals that are construed with null spatial Ps are special in that they are associated with the silent locative noun PLACE; as a result, they raise to the specifier position of $\mathrm{P}$ and satisfy its lexicalization requirements, with the consequence that $P$ surfaces without phonetic content. Other elements that are also complements of null spatial Ps are the (run-of-the-mill) locative adverbials; these are the modifiers of PLACE (Kayne 2004, 2005) and also raise to the specifier of the spatial P, with the consequence that $\mathrm{P}$ surfaces without phonetic content. The 'nominal' arguments of null spatial Ps are thus rendered more similar to locative adverbials, than to their homophonous common nouns. The latter are the nouns that are encountered with an overt determiner as arguments of overt spatial Ps and, according to our views, are the possessors of the silent noun PLACE.

The paper is structured as follows: section 2 presents the facts that have been discussed in the literature and the accounts of the phenomenon that have been based on them. Section 3 examines primarily facts from Greek as far as the properties of the participating spatial Ps are concerned, while section 4 focuses on the properties of the nominals associated with null Ps. Finally, section 5 presents the proposed analysis.

\section{The facts}

\subsection{The facts in Greek}

The Greek noun spiti 'home', along with a number of other nouns to which we will return, participates in constructions such as in (1a), in which the directional (or locative) P se is optionally present. ${ }^{1}$ Greek, unlike English, but like the Italian dialects that also manifest the phenomenon, has at its disposal one and the same word, i.e., spiti, for both 'home', (1a), and 'house', (1b):

1. In (1), as well as in most other examples, the Greek directional/locative $\mathrm{P}$ se appears as $s$, since this is its contracted form before the definite determiner. 
(1) a. I Maria girise (sto) spiti arga. the Maria returned se.the home late 'Maria got home late.'

b. I Maria agorase kenurio spiti sti thalassa. the Maria bought new house se.the sea 'Mary bought a new house by the sea.'

The first to discuss the syntax of Greek spiti as the complement of an optionally present directional $P$, namely, in contexts such as (1a), were Ioannidou and den Dikken (2006), (henceforth, I\&D). ${ }^{2}$ Based on a number of arguments and diagnostics, they conclude that a directional $\mathrm{P}$ is syntactically present in (1a), despite the fact that it has no phonetic content, a view this work fully shares with them. Subsequently, I\&D claim that the null $\mathrm{P}$ is licensed via incorporation into $\mathrm{V}$, a claim supported by the fact that no null $\mathrm{P}$ is possible with particle verbs, i.e., ana-dyome 'emerge' - in a manner reminiscent of den Dikken's 1995 verb-particle constructions, where intervening particles also block P-to-V incorporation. As for the noun of the construction, they consider it part of a DP with a full-blown syntactic structure which, in order to have its case feature valued in the absence of an overt $\mathrm{P}$, moves to Spec, DP - satisfying at the same time the (alleged) EPP property of the Greek D. Since NP moves to Spec, DP, Dx (in terms of Pesetsky and Torrego 2001) does not move to $\mathrm{D}$, and the definite article is not spelled out when spiti raises this is why the definite article cannot be present when se is not phonetically realized. The authors do not miss to point out that the DP argument of a null $\mathrm{P}$ cannot be modified: they consider this property to follow from the specifics of the NP-toSpec, DP movement they propose, in association with den Dikken's (2006) Vacuous Movement Hypothesis (which does not allow movement that skips material without phonological or semantic content). The reason why the nominal complements of null Ps can (only) be modified by a possessor is because possessors can be expressed as clitics in Greek; these are (reasonably) taken to adjoin to D, which then has phonetic content when NP-to-Spec, DP movement crosses it, thus respecting the Vacuous Movement Hypothesis.

\subsection{Beyond Greek}

It turns out that null Ps, a term used through the paper along with the terms 'Ps without phonetic content' or 'silent Ps', are not unique to Greek in contexts such as the above. Such Ps are also present in English, for instance, although by far less commonly, since a null $\mathrm{P}$ is possible only when its ground or goal argument is home. Moreover, while a null $\mathrm{P}$ is optional with 'at', it is obligatory with 'to' (2).

2. An earlier discussion of the phenomenon, focusing on the interpretation of the nominals of the structure primarily, is offered by Valiouli and Psaltou-Joyce (1994). 
(2) a. He stayed (at) home

b. He went (*to) home early.

Nevertheless, home appears as a bare noun in English as well, and a null P is not possible when the PP it heads is an adjunct.

\section{(3) I did my homework *(at) home}

A substantially different account than the one presented in the previous section is offered by Collins (2007) for English null Ps, centering on both, properties of the Ps that remain unpronounced and of the noun home. The gist of Collins' proposal is that Ps can remain unpronounced as long as their Edge is overt, a requirement that is satisfied when the argument of the null $\mathrm{P}$ is home because the latter is the type of nominal that is able to move to the specifier of $\mathrm{P}$ and render it overt. Although the reasons that trigger such a movement are not entirely clear, it is a movement contingent upon the special status of home as a 'light' noun - which for Collins (2007) amounts to a noun with reduced syntactic structure, a property that is also used to explain the fact that it cannot be modified and it is not construed with a determiner. In other words, by being the noun it is, home is able to raise all the way to the specifier of the $\mathrm{P}$ that introduces it, with the consequence that the Edge of PP obtains phonetic content. A similar type of movement is not possible for ordinary nouns, therefore, the Edge of PP cannot be overt unless $\mathrm{P}$ itself lexicalizes its head position.

(4) a. He stayed *(at) the museum.

b. He went $*$ (to) the museum.

It should be noted here that, although the properties of home are not made entirely clear in this account, except perhaps from the fact that it has a reduced syntactic structure, its resemblance to locative elements such as here and there is nevertheless pointed out. As a matter of fact, as Collins himself also acknowledges, the idea of home raising to Spec, $\mathrm{P}$ is in the spirit of van Riemsdijk (1978) with respect to Dutch here/there, which belong to the set of elements known as r-pronouns. ${ }^{3}$

Turning to languages other than English and Greek, the phenomenon is mentioned by Longobardi (2001) with reference to the modern Veneto dialects:

(5) Vago casa (mia)

I am going home (my)

3. As Collins notes, the Dutch elements van Riemsdijk (1978) discusses are a subset of those that can be construed with a null $\mathrm{P}$ in English. 
Longobardi's focus in the above work is the status of casa/ca 'house/home', but not in the context of PPs. Nevertheless, he associates in passing the special status of $c a s a / c a$ ' with its ability to occur as the object of null Ps, and conjectures that only nouns of the 'construct state' type are able to occur with null Ps. It is interesting that Longobardi as well refers to this instance of Romance home as a locative adverb (which, again, brings it close to the English here and there in Collins' account).

A complete description of the phenomenon in Romance, as manifested by the Northern Italian Dialects, as well as an account of it, does not appear until recently, however, namely, with Cattaneo's (2009) study of two Northern Italian Dialects: Bellinzonese (spoken in Switzerland) and Paduan. A difference between the two varieties is that a null $\mathrm{P}$ in the relevant contexts is obligatory in Paduan but optional in Bellinzonese with both locative and directional Ps. A similarity that the two varieties share, also present in Greek, is that the same lexical form, i.e., $a$, is employed with both locatives and directionals. Cattaneo considers $a$ to be a locative $\mathrm{P}$, which is preceded by an unpronounced $\mathrm{TO}$ when it gets a directional interpretation (a view shared by this work with respect to the Greek P se, which also surfaces as either a locative or a directional goal P). ${ }^{4}$

(6) a. Te scte (a) ca'.

(Bellinzonese)

cl stay at home

'You stay at home.'

b. Te vé (a) ca'.

cl go to home

'You go home.'

(7)

a. Stago (*a) caza.

stay at home

(Paduan)

'I stay at home.'

b. Vago (*a) caza.

go to home

'I go home.'

The analysis Cattaneo advocates is in the spirit of Collins' (2007) in that he also considers northern Italian home, along with other nouns that may appear in (6) and (7), to have the status of a light noun, by virtue of which they move to Spec,

4. With the exception of English, where null Ps are only possible with home, however, null spatial Ps seem to be available only in languages which utilize the same P for 'to' and 'at', as is the case for Bellinzoneze, Greek and Paduan (and also Venician, as Anna Cardinaletti informs me). To be precise, it seems that this condition is necessary, although not sufficient, for the phenomenon to be manifested: Catalan, for instance, utilizes $a$ in both cases, i.e., vaig a casa/ca 'I'm going home', sóc a casa 'I am at home', but a cannot surface without phonetic content (Josep Quer p.c.). The same holds for standard Italian. 
PP and render its Edge overt, hence, the locative or directional P remains without phonetic content. $^{5}$

We detect therefore, two approaches to the phenomenon under investigation: the first, which is based on facts from Greek primarily, holds that what is going on is intimately related to the lack of phonetic content of the spatial $\mathrm{P}$, and subsequent accommodations occur in order for the associated noun to check its case feature. The second view is based on facts from English and the Italian dialects, which do not differ significantly from Greek in the relevant respects, however, and is essentially an account of the lexicalization requirements that hold of spatial Ps. An important ingredient of this view, and a point of divergence from the previous one, is that it attributes a particular status to the nominals that are encountered as arguments of such Ps. These are taken to be exceptional in the sense that they are capable of satisfying the lexicalization requirements of spatial Ps in a manner common nouns cannot. In this work, we will demonstrate that the properties of such nouns are indeed different from those of ordinary nouns in ways that are crucially implicated in the manifestation of the phenomenon - despite the fact that they are not solely responsible for it. Before doing this, however, we will focus in the following section on the types of spatial Ps that may be encountered without phonetic content, as it is an issue that has been overlooked by the existing accounts.

\section{Types of null Ps}

\subsection{Null locative Ps}

The sentences in (8) below essentially repeat the phenomenon, demonstrating than when spiti 'home' is the complement of the locative $\mathrm{P} s e$ in Greek, this $\mathrm{P}$ is optional. It is also demonstrated that the possibility of omitting se arises for a number of ground arguments other than spiti, although we detect a slight grammaticality difference between them and spiti, cf. (8a) vs. (8b). In other words, spiti is much more acceptable with a silent $\mathrm{P}$ when construed with verbs such as ime 'be', meno 'stay/live' as compared to the rest of the nominals. Such a grammaticality difference is not replicated by the various nominal arguments of the null directional goal P, as we will see in the following section.

5. On the other hand, the optionality of Bellinzonese Ps and of English 'at' is attributed to the fact that the nominal identified as 'light' noun is also possible as a bare noun. The latter does not raise up to Spec, P, hence, P must be overt (while the noun still does not have a determiner). Presumably, the Catalan casa in the previous footnote is similar in this respect. One wonders, however, what is the source of the postnominal possessor in this case, as J. Sola[à] (p.c.) points out, i.e., a casa meva vs. a la meva casa. That is, if casa is a bare noun in a casa meva, as suggested by the presence of the $\mathrm{P}$ and the absence of the determiner, how come the possessive appears after casa? In other words, if postverbal possessors are the result of noun movement past the possessor, how come this movement does not also result in a silent P? Obviously, more detailed investigation is required in order to answer. Nevertheless, it is worth pointing out that even in Bellinzonese, where silent Ps are quite common, hence, movement of the relevant light nouns as well, home is the only noun that appears with a postnominal possessor. 
(8) a. Emina (sto) spiti mexri arga. stayed-1s se.the home until late 'I stayed home until late.'

b. Emina ?(sto/ti) gymnastirio/sxolio/grafio/eklisia mexri arga stayed-1s (se.the-neu/fem) gym/school/office/church until late 'I stayed at the gym/school/office/church until late.'

Concentrating on the variant without se, we assume that a locative $\mathrm{P}$ is syntactically present but lacks phonetic content, as demonstrated in (9), to be further refined in section $5:^{6}$

(9) Emina $\left[{ }_{\text {PPLoc }}\left[\left[_{\text {PLoc }} s e / 0\left[_{\mathrm{DP}}\right.\right.\right.\right.$ spiti $\left.\left.]\right]\right]$

A comparable, although much more pronounced, picture differentiating spiti from other nominals is obtained when non-motion verbs are followed by a locative PP that is an adjunct. The sentences in (10) demonstrate that with verbs such as magirevo 'cook', troo 'eat', etc., a null $\mathrm{P}$ is not possible with nouns other than spiti.

(10) a. Sinithos magirevo/troo (sto) spiti usually cook-1s/eat-1s se.the home 'I usually cook/eat at home.'

b. Sinithos troo *(sto) gymnastirio/sxolio/grafio usually eat-1s se.the gym/school/office 'I usually eat at the gym/school/office.'7

\subsection{Null directional Ps}

As already mentioned, a spatial $\mathrm{P}$ may be missing also when it follows a motion verb, in which case we consider the null $\mathrm{P}$ to be of the directional goal type, (11).

(11) a. Pao (sto/sti) spiti/gimnastirio/sxolio/grafio/eklisia. go-1s (se.the-neut/fem) home/gym/school/office/church

b. Pao $\left[_{\mathrm{PPDir}}\left[{ }_{\mathrm{PDir}} 0\left[_{\mathrm{PPLoc}}\left[{ }_{\mathrm{PLoc}}\right.\right.\right.\right.$ se/0 [ $\mathrm{DP}$ spiti $\left.\left.\left.]\right]\right]\right]$

6. See I\& D (2006) for a series of arguments as to why a P is syntactically present in the relevant context, even when it does not have phonetic content.

7. Two of the four native speakers with whom I checked the data accept a null $\mathrm{P}$ with school in (8b) (but not with the other nouns). After looking at the example(s) again, I still do not find school acceptable, nevertheless, it is less dreadful than with the other two nouns. The ungrammaticality of the examples cannot possibly be attributed to pragmatic factors such as that cooking or eating is not compatible with a place such as the gym or church, for instance, since gimnazome *(sto) gymnastirio 'I exercise at the gym' is also ungrammatical with a null P. Besides, it should always be kept in mind that the expressions are fully grammatical with an overt se. 
Unlike with locatives, the possibility of omitting se does not only hold for when the argument of $\mathrm{P}$ is spiti, but for a number of other nominal arguments as well, without any difference in grammaticality. Moreover, it also holds for a number of directed motion verbs, such as: pigeno/pao 'go', girizo, epistrefo 'return', etc. It should be reminded that se is also the lexical item that serves as a locative $\mathrm{P},(8)$ (10). As mentioned in passing in section 2, it is assumed that $s e$ is always locative, and that the different interpretation between (8) and (11a) results from the presence of a null goal $\mathrm{P}$ in the latter, cf. (9) vs. (11b). ${ }^{8}$ Note that, by making this assumption, we are essentially saying that the goal $\mathrm{P}$ is always devoid of phonetic content in Greek, regardless of whether the locative $\mathrm{P}$ that follows it is overt or not. This point will come up again in section 5.2, where we attempt a correlation of the phenomenon of null Ps with the fact the locative and directional Ps have identical phonetic shape.

Notice now that while a directional goal $\mathrm{P}$ has the option of remaining null, the same option is not available when the directional $\mathrm{P}$ is of the source type, i.e., apo 'from':

(12) Efiga *(apo to) spiti/grafio/etc. left-1s from the home/office, etc.

Hence, while erxome 'come' is compatible with either se or apo when these are overt, (13), the only interpretation available when the same verb is followed by a null $\mathrm{P}$ is the goal interpretation, i.e., I come to the office below.

(13) a. Erxome (sto) spiti/grafio/etc. come-1s to.the home/office/etc. 'I come home/to the office/etc.'

b. Erxome *(apo to) spiti/office/etc. come-1s from the home/office/etc. 'I come from home/from the office/etc.'

It should be pointed out here that a null $\mathrm{P}$ cannot have (directional) source interpretation in English or the Italian dialects either, as the example below from Bellinzonese demonstrates (Cattaneo p.c.). Alternatively put, a directional source $\mathrm{P}$ must always have phonetic content.

(14) Vegni (a) ca'

come-1s a home

'I come home.'

8. Se is also the $\mathbf{P}$ of ditransitives (see Anagnostopoulou 2003, 2005). It is because of all the different contexts in which $s e$ is encountered that Anagnostopoulou (2005) considers it to have unspecified features. Obviously, the view we adopt here is different, at least when it comes to the spatial uses of $s e$ : instead of considering it to instantiate either $\mathrm{P}_{\mathrm{Loc}}$ or $\mathrm{P}_{\text {Goal }}$, hence, to be unspecified for location or direction, we take it to only stand for the former. 
From a descriptive point of view, and if we take into account recent claims with respect to the relative order within the fine grained architecture of spatial Ps, cf. (15), (see Pantcheva (to appear), Svenonius (2010), and Cinque (2010)), we see that the Ps that may surface without phonetic content, i.e., the locative and directional goal Ps that are in bold in (15) below, are adjacent in the syntactic structure and occupy the lower parts of it. This structure, which has been proposed on independent grounds, has the potential of attributing the impossibility of a null source $\mathrm{P}$ to its position within the extended spatial $\mathrm{P}$ projection, rather than its semantic input. ${ }^{9}$

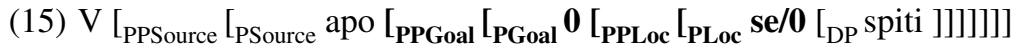

Notice however, that it looks as if a locative null $\mathrm{P}$ is not possible when it has a specific type of locative interpretation, namely, when it is associated with containment, or else, what English expresses by 'in'. We should note here that Greek $s e$ stands for both 'at' and 'in', (16a)-(16b). The contrast in (17a) vs. (17b) shows that it cannot be null in the latter case.

(16) a. To sxolio ine stin paralia. the school is at-the promenade

b. Ta luludia ine sto anthodoxio. the flowers are in-the flower pot

(17) a. Imun (sto) gimnastirio otan egine o sismos. was se.the gym when occurred the earthquake 'I was at the gym when the earthquake occurred.'

b. Imun *(sto) aftokinito otan egine o sismos. was se.the car when occurred the earthquake 'I was in the car when the earthquake occurred.'

Some other nouns that are also impossible in the context of a null $\mathrm{P}$ are thalamos '(phone) booth', kuti 'box', etc. all of which express containment and are selected by 'in' in languages with a morphological distinction between 'at' and 'in'. 10

9. We leave open the question of whether there is a deeper reason why $\mathrm{P}_{\text {Goal, }}$ but not $\mathrm{P}_{\text {Source }}$, can surface without phonetic content Nevertheless, it is the right place to point out that this is not the only domain in which judgements and performance with respect to the two directional Ps differ. In large scale experimental research Lakusta and Landau (2005) find a consistent preference for encoding goals in contexts where either a goal or source interpretation is possible, e.g., (13).

10. Note that those nominals that are selected by the spatial $P$ 'in' in Bellinzonese cannot occur as the complements of a null P either, as Cattaneo (2009: p. 267) reports:

(i) Al va *(in) libreria/palèsctra/preson cl goes in bookstore/gym/prison 'He goes to bookstore/gym/prison.' 
In line with what we said previously, it is conceivable that the two types of locative Ps, i.e., 'at' and 'in', occupy different positions in the spatial P structure as has indeed been suggested by Cinque (2010), who places 'in' in a lower, position than 'at'. If this is indeed the case, although it looks suspicious that the two Ps that are able to occur without phonetic content, i.e., $\mathrm{P}_{\text {Goal }}$ and 'at', make up an intermediate part of the structure in (15), with the higher and the lower parts of it, i.e., $\mathrm{P}_{\text {Source }}$ and 'in' respectively, resisting a null variant, one maybe still be able to offer a syntactic account of their surfacing without phonetic content (based on their position within the spatial $\mathrm{P}$ architecture). As for the ungrammaticality of (17b) in particular, however, it will soon be demonstrated that it is unlikely to be related to the fact that the spatial $\mathrm{P}$ expresses containment (or, at least, only to this fact).

Concluding this section, it emerges that the spatial Ps that may occur without phonetic content are 'to' and 'at', most probably, only when they happen to be homophonous in a certain language. The rest of spatial Ps resist a null variant, even in a language such as Greek in which null Ps are rather common. As to why these are the only such Ps, we have not been able to provide an interesting answer. For this reason, we will now shift our attention to the nominal complements of the spatial Ps that have a null counterpart, as we think there is something more concrete to be said about them. It should be kept in mind however that the mere fact that not all Ps in (15) can surface without phonetic content suggests that the phenomenon of null Ps does not only depend on the nature of their nominal complements, which indeed seem to be exceptional as we will claim, but on the Ps themselves as well. We believe that this aspect of the behaviour of null spatial Ps should be the first to be investigated in future research on the topic.

\section{Nouns that may appear with null Ps}

In the previous section we discussed the spatial Ps that may occur without phonetic content and, briefly, those that may not. This section focuses on the nouns that may appear as the ground or goal arguments of null Ps.

\subsection{Home vs. other nouns}

As mentioned in various occasions already, the quintessential nominal that is encountered as the complement of a null $\mathrm{P}$ is home. Some languages, i.e., English, employ a dedicated item in this context, i.e., home (vs. house). Others, such as Greek or the Romance do not, as (1), repeated below, demonstrates.

(1) a. I Maria girise (sto) spiti arga. the Maria returned se.the home late 'Maria got home late.'

c. Maria agorase kenurio spiti sti thalassa. the Maria bought new house se.the sea 'Mary bought a new house at/by the sea.' 
Home is the only nominal that one may encounter as the complement of a null spatial P in English. On the other hand, spiti is the nominal most widely accepted with null spatial Ps in Greek in two respects at least: a) it is more felicitous when compared to other nominals as the ground argument of a null complement locative $\mathrm{P}$ and $\mathrm{b}$ ) it is the only nominal accepted as the ground argument of a null adjunct locative P, (8)-(10).

Finally, spiti is the only nominal that may appear with a modifier, in particular, accompanied by the possessive pronoun, (18a). Notice that in Bellinzonese as well, $c a$ ' is the only noun that occurs with the possessive pronoun, (18b), by contrast to English where modification of home even by pronominal possessors is unavailable, (18c)).

(18) a. Ime (sto) spiti mu/tu/tis/etc.

am se.the home my/his/her/etc.

'I am at my/his/her/etc. place.'

b. Sctò (a)ca mia.

stay at home my

'I stay at my place.'

Catanneo (2009: p. 283)

c. I go (*my) home (*my).

As Cattaneo (p.c.) reports, $c a^{\prime}$ is also the only nominal that is able to appear as the complement of a null locative $\mathrm{P}$ in Bellinzonese, by contrast to the directional $\mathrm{P}$ which may surface null even when followed by nominals such as scòla 'school', military 'army', teatru 'theater'. Hence, home is exceptional when compared to other nominals, in that it may occur as the argument of a null spatial $\mathrm{P}$ in contexts other nominals cannot. With this in mind, let us see below how other nominals behave. We focus primarily on Greek from this point on, since it appears to be the language that allows for a wider spectrum of such nominals.

\subsection{The Place aspect}

We have already mentioned that a number of nominals other than spiti can appear as ground or goal arguments of null spatial Ps in Greek, cf. (8b), (11a) repeated below as (19):

(19) a. Emina ?(sto/ti) gymnastirio/sxolio/grafio/eklisia mexri arga stayed-1s ?(se.the-neut/fem) gym/school/office/church until late

b. Pao (sto/sti) spiti/gymnastirio/sxolio/grafio/eklisia. go-1s (se.the-neut/fem) home/gym/school/office/church

Recall (17b) now, in which the ground argument of the null locative is aftokinito 'car'. Note that this noun cannot appear as the argument of a null goal P either, although goal Ps are the most easily alternating with their null variant, cf. (19). 
Other nouns that cannot surface as the goal or ground arguments of null Ps also refer to means of transportation, (20a), and they are all perfectly grammatical when the spatial $\mathrm{P}$ that introduces them is overt.

(20) a. Pao/ime *(sto) treno/leoforio/plio/aeroplano, etc. go-1s/am se.the train/bus/ship/airplane, etc.

b. Pao/ime (sto) stathmo/limani/aerodromio. go-1s/am se.the station/port/airport.

Let us focus for a moment on the grammaticality contrast between (20a) and (20b) above, as we believe it is important for pinpointing a property that characterizes the type of nouns that are able to surface as arguments of a null spatial P: notice that if the nominal argument of the directional or locative $\mathrm{P}$ is stathmos 'station', limani 'port', aerodromio 'airport', (20b), which practically stand for the final destination or point of departure of the means of transportation in (20a), a null P is grammatical. A manner in which we see the nouns in (20b) to differ from those in (20a), is that they refer to places or locations. We will use the term place nominals here in order to refer to those nominals that denote a location (or place). The nominals in (19), all of which are grammatical with a null P, refer to places or locations as well. ${ }^{11}$

Other elements that one can reasonably consider to fall within the category of place/location nominals as sketched above are place names. These are widely employed with null Ps, as demonstrated in (21). It should be noted that place names, along with proper names are construed with the definite determiner in Greek. Nevertheless, they are perfectly grammatical without the definite determiner when following a null $\mathrm{P}$.

11. But notice that not all place nominals can appear as the complements of a null P. We believe the difference between the place nouns in (19) and (20b) and those in (i) below, can be best captured in terms of a part/whole distinction. In other words, it seems that some ban on parts (of places), by contrast to wholes, is imposed, hence the contrast between (ia) and (ib)-(ic).

(i) a. Imun (sto) spiti/grafio otan egine o sismos.

was-1s se.the home/office when occurred the earthquake

'I was at home/at the office when the earthquake occurred.'

b. Imun *(stin) kuzina otan egine o sismos.

was-1s se.the kitchen when occurred the earthquake

'I was in the kitchen when the earthquake occurred.'

c. Imun *(sto) balkoni otan egine o sismos.

was-1s se.the balcony when occurred the earthquake

'I was at the balcony when the earthquake occurred.'

A similar ban holds for other parts of the house, such as kipos 'garden', garage 'garage', ipogio 'basement', etc. Similar considerations hold for parts of the other places in (8a) that were grammatical, namely, apoditiria 'dressing rooms' vs. gimnastirio 'gym', etc. For the time being we will leave this property aside and stick to the general observation that the nominals that are able to occur as the complements of a null spatial $\mathrm{P}$ are the ones that refer to places (or locations). 
(21) (Avrio) pao (stin/sto) Athina/Thessaloniki/ Olympia/Volo/etc. (tomorrow) go-1s se.the Athens/Thessaloniki/Olympia/Volos/ etc.

The very same type of nouns can be used with a null spatial in Bellinzonese as well, as Cattaneo (2009) reports:

(22) Te scte/ve (a) Belinzona/Locarno/Lügan/Milan/Turin/Venezia/Paris you stay/go at/to Bellinzona/Locarno/Lugano/Milan/Turin/Venice/Paris ${ }^{12}$

Therefore, although certain restrictions seem to apply, as noted in footnotes 11 and 12 , the nominals that are able to surface as the complements of null Ps must refer to places or locations.

\section{An explanation for null spatial Ps}

To anticipate the main ideas to be developed in the remainder of the paper, the occurrence of spatial Ps without phonetic content is considered to be intimately related to the status of the nominal arguments of such Ps, more specifically, to the fact that they refer to places or locations. What is attempted here is to translate this property syntactically in a very specific manner, namely, in terms of considering such nouns to be associated with the silent noun PLACE. The latter is a nominal which has been claimed to also have a silent determiner and raise higher in the structure it occurs than common nouns. The proposal to be developed is that the nominals that appear as complements of a null $\mathrm{P}$ are either the instantiation of PLACE or its modifiers and it is precisely their ability to move all the way to the specifier of the selecting locative or directional $\mathrm{P}$ that allows this $\mathrm{P}$ to remain without phonetic content. The lack of an overt determiner is a characteristic property of PLACE, and presumably contributes to the different interpretation of the nouns

12. Cattaneo notices an interesting differentiation between place names that can be construed with a null $\mathrm{P}$ and those that cannot: the former must be familiar to the speaker (or be tied to habitual places and periods of a community life). Hence, cities such as Rome, Palermo, Amsterdam, New York, etc. cannot surface in (22). No similar restrictions apply to Greek place names.

Nevertheless, we believe that a notion of familiarity is at play in Greek as well and needs to be investigated. Consider the pair below, for instance, in which the noun xorio 'village' is employed in Greek. While both (ia) and (ib) are grammatical, the former may be used only when talking to people who know which/where the town of the speaker is.

(i) a. Pao xorio $(* m u)$.

go-1s village my

b. Pao sto xorio $(\mathrm{mu})$

go-1s se.the village my

'I go to my village.'

It should also be noted that, although xorio is somehow similar in interpretation to spiti (in the sense of 'birthplace'), it cannot be construed with the possessive clitic in the context of a null P, (ia). This indicates again the unique behavior of spiti when compared with other place nominals associated with null Ps. 
that are associated with it from that of common nouns (most importantly the homophonous ones). Before looking a bit more closely into these nominals however, let us introduce some notions and background assumptions that are necessary in order to demonstrate how their interaction with the selecting $\mathrm{P}$ results in the phenomenon of null Ps.

\subsection{Background assumptions}

According to Collins (2007), English spatial Ps are able to surface without phonetic content in the presence of home because the latter can satisfy their lexicalization requirements, articulated in (23) below ${ }^{13}$, with $\mathrm{X}$ standing for $\mathrm{P}$ as well.

(23) a. Edge(X) must be phonetically overt.

b. the condition in (a) applies in a minimal way, so that either the head or the Specifier, but not both, are spelled out overtly.

Collins holds that when a spatial P remains silent in English it is because the noun home moves into its specifier position and renders its Edge phonetically overt. Nchare and Terzi (2010a) provide evidence that the principle in (23) can be satisfied not only via movement to Spec, $\mathrm{P}$, but also via external merge of some other element(s), which in the case of Shupamem (a Bantu language of Cameroon) are the elements they label Logophoric Modifiers. ${ }^{14}$ The importance of the latter claim lies in the fact that (23) is rendered less unusual that what one may be tempted to think at first glance, since, when matched with the possibility of external merge that renders the Edge of $\mathrm{P}$ overt, it amounts to nothing more than EPP phenomena, argued to also be present in the (spatial) P domain, Nchare and Terzi (2010b).

In addition to the requirements pertaining to the lexicalization of the structure of spatial Ps, (23), I adopt proposals in Terzi $(2008,2010)$ with respect to the structure of locative Ps, illustrated in (24). According to (24), the structure of a locative $\mathrm{P}$ consists of a functional head $\mathrm{P}_{\mathrm{Loc}}$, which takes as its complement an empty nominal, PLACE.

(24) $\left[_{\mathrm{PPLoc}}\left[\left[_{\mathrm{PLoc}} 0\left[_{\mathrm{DP}} 0\left[_{\mathrm{XP}}\right.\right.\right.\right.\right.$ locative $\left[_{\mathrm{NP}} \mathrm{PLACE}\left[{ }_{\mathrm{DP}}\right.\right.$ ground argument $\left.\left.\left.\left.]\right]\right]\right]\right]$

In languages such as Greek, what are often considered (transitive) locative Ps are the modifiers of PLACE, (25). Similar considerations are also claimed to hold for the Spanish and English counterparts of the Greek example(s) below.

13. Reminiscent of the Doubly Filled Comp Filter (Keyser 1975), as Collins himself also acknowledges.

14. These are elements that Nchare and Terzi (2010) demonstrate to refer to speaker's point of view with respect to the scene described by the spatial $\mathrm{P}$. 
(25)

$$
\begin{gathered}
{\left[_{\mathrm{PPLoc}}\left[{ }_{\mathrm{PLoc}} 0\left[_{\mathrm{DP}} 0\left[{ }_{\mathrm{XP}} \text { piso/epano/dipla }\left[_{\mathrm{NP}} \mathrm{PLACE}\left[_{\mathrm{DP}} t u\right]\right]\right]\right]\right]\right.} \\
\text { behind/on/beside }
\end{gathered}
$$

\section{'behind/on/beside him'}

In languages such as Shupamem on the other hand, locative Ps instantiate, rather than modify PLACE, with the consequence that the latter is not silent anymore, while the rest of the structure remains essentially the same (Nchare and Terzi 2010).

$$
\begin{gathered}
{\left[_{\mathrm{PPLoc}}\left[\left[_{\mathrm{PLoc}} 0\left[_{\mathrm{DP}}\left[0\left[_{\mathrm{NP}} \text { ndún/nJin }\left[_{\mathrm{DP}} \text { tèbè }\right]\right]\right]\right]\right]\right]\right.} \\
\text { top/root table }
\end{gathered}
$$

'on/under the table'

Finally, the ground argument of a locative $\mathrm{P}$ is considered the possessor of PLACE (or of its overt counterpart) in both types of languages.

It should be reminded that PLACE is just one of the silent elements proposed in Kayne (2005), and was first introduced in Kayne (2004) as a silent noun that is modified by adverbials such as here and there, so that the structure of here and there is as in (27):

\section{${ }_{\mathrm{DP}}\left[{ }_{\mathrm{D}} 0\left[_{\mathrm{XP}}\right.\right.$ here/there $\left[{ }_{\mathrm{NP}}\right.$ PLACE $\left.\left.\left.]\right]\right]\right]$}

According to Kayne (2004), PLACE, with its modifiers, raises past D, and must be licensed by a locative adposition. Terzi $(2008,2010)$ provides evidence from Greek according to which PLACE is indeed selected by a locative adposition, as already seen in (24). One of the points to be kept in mind while dealing with (27) is that the D position of PLACE is also silent. The reasons for this are not clear in Kayne (2004, 2005), while for Collins (2007) they follow from the fact that it is a 'light' noun, and, as such, it has a reduced syntactic structure. We will not elaborate further on this (very important) issue here, but take for granted that PLACE or its overt counterpart, are associated with a null $\mathrm{D}$, remaining agnostic as to whether this $\mathrm{D}$ is syntactically present but silent or is entirely absent - and what the effect of this difference is on the special behaviour of the 'nominals' under investigation.

\subsection{The arguments of null Ps are the instantiation of PLACE}

Shupamem presents particular interest for the ideas expressed in this paper, since the very same noun, tú 'head' below, for instance, can be either a (transitive) locative element, part of the structure of the locative PP, (28a), or a common noun, which is the ground argument of the locative P, (28b). Nchare and Terzi (2010) make explicit that the different interpretation of the very same lexical item in each case reflects the two (different) syntactic structures in which it occurs, i.e., (28a) vs. (28b). 
(28) a. $\left[_{\text {PPLoc }}\left[\left[_{\text {PLoc }}\right.\right.\right.$ mè $\left[_{\text {DP/NP }}\right.$ tú $\left[_{\mathrm{DP}}\right.$ John $\left.\left.]\right]\right]$ 'above John'

$$
m \text { mè head John }
$$

b. $\left[_{\text {PPLoc }}\left[{ }_{\text {PLoc }}\right.\right.$ mè $\left[_{\text {DP/NP }}\right.$ PLACE $\left[{ }_{D P}\right.$ tú $\left.\left.\left.]\right]\right]\right]$

$m \grave{e} \quad 0 \quad$ head

'on the head'

A core idea that I would like to convey in this respect is that the nominals that are encountered as arguments of a null spatial P in Greek are more like 'head' in (28a), rather than the common noun 'head' of (28b), differing from the former only in that they are not associated with a ground argument (that is, that they are not transitive).

Let us now see exactly how the above ideas are implemented, starting with a locative PP whose head $\mathrm{P}$ is null and is the complement of a stative verb that expresses location, cf. (8) repeated below.

(8) a. Emina (sto) spiti mexri arga.

stayed-1s se.the home until late

'I stayed home until late.'

b. Emina ?(sto/ti) gymnastirio/sxolio/grafio/eklisia mexri arga stayed-1s (se.the-neu/fem) gym/school/office/church until late 'I stayed at the gym/school/office/church until late.'

The structure of (8) is as in (29) below, with the nominal argument(s) of the null $\mathrm{P}$ to instantiate PLACE.

(29) $\mathrm{V}\left[_{\mathrm{PPLoc}}\left[{ }_{\mathrm{PLoc}} 0\left[_{\mathrm{DP} / \mathrm{NP}}\right.\right.\right.$ spiti/grafio/etc. $\left.\left.]\right]\right]$

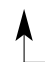

According to (23), the Edge of $\mathrm{P}_{\text {Loc }}$ has to be overt, but neither $\mathrm{P}$ nor its specifier, have phonetic content if $s e$ is not present, as is indeed the case in (29). Inevitably, something else has to render the Edge of $\mathrm{P}$ overt and such elements are the nominals that instantiate PLACE, which move to Spec, $\mathrm{P}_{\text {Loc }}$ as indicated in (29). Subsequent movement of $\mathrm{PP}_{\text {Loc }}$ into Spec, PredP, (30), takes place (and explains the impossibility of adjunct place nominals with a null locative $\mathrm{P}$, as will be demonstrated shortly). ${ }^{15}$

15. See both, Collins (2007) and Ioannidou \& den Dikken (2006), for an additional step of movement, i.e., of PP (or P) moving up to the verbal domain. For Collins this step provides the means for the 'light' NP to receive case, and it involves movement of the (null) spatial PP into the specifier of PredP (which is the complement of v), explaining the unavailability of null Ps which are adjuncts. 
(30) Pred $\left[{ }_{\mathrm{VP}} \mathrm{V}\left[_{\mathrm{PPLoc}}\left[\left[_{\mathrm{PLoc}} 0\left[_{\mathrm{DP} / \mathrm{NP}}\right.\right.\right.\right.\right.$ spiti/grafio $\left.\left.\left.]\right]\right]\right]$

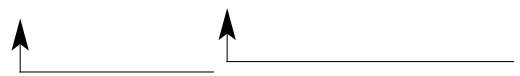

Similar considerations hold for goal PPs. The difference this time is that there is one more level of embedding, since we adopt the structure in (15) for directional Ps, repeated below slightly modified as (31). According to (31) a directional goal P selects for a locative $\mathrm{P}$ :

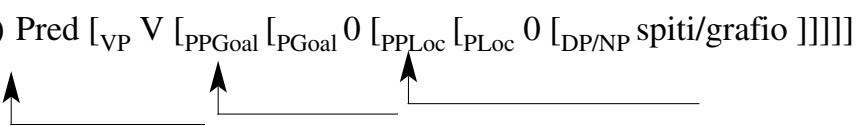

Two remarks are in order given the above structures and the associated proposals: since we adopt (23) as a principle that operates on the structure of spatial Ps, we are led to assume that movement of $\mathrm{PP}_{\mathrm{Loc}}$ to Spec, $\mathrm{P}_{\mathrm{Goal}}$ takes place in order for the Edge of $\mathrm{PP}_{\text {Goal }}$ to obtain phonetic content in Greek even when the argument of $\mathrm{P}_{\mathrm{Loc}}$ is not a place nominal. This state of affairs may offer an understanding of why silent locative and goal Ps are encountered only in languages where the two are (apparently) homophonous; if in such occasions what actually happens is not that the two Ps are homophonous, but that the higher one, i.e., $\mathrm{P}_{\mathrm{Goal}}$ is silent, $\mathrm{P}_{\mathrm{Loc}}$ always has to raise to its specifier position in order to lexicalize it. This of course cannot be the whole story, as we still do not know why some languages allow $\mathrm{P}_{\mathrm{Loc}}$ to surface without phonetic content to start with while others don't. ${ }^{16}$

Furthermore, the fact that place nominals surface as arguments of directional Ps supports the idea that a locative $\mathrm{P}$ is present, i.e., it is selected by a directional $\mathrm{P}$, even when the latter is not seen - given that we consider place nominals, as elements that instantiate or modify PLACE, and PLACE to be selected by $\mathrm{P}_{\text {Loc }}$. Alternatively speaking, the presence of place nominals as arguments of directional Ps supports the fine grained architecture of spatial Ps that we have adopted in $(15)=(31)$, which has been proposed on independent grounds.

Before we continue, let us clarify one more point: recall that all instances of null spatial Ps in Greek, (32a), have a counterpart in which the spatial P is overt (and its nominal argument is introduced by an overt determiner), (32b):

(32) a. Ime grafio

am office

b. Ime sto grafio

am se.the office

'I am at the office.'

I\&D (2006) on the other hand assume incorporation of the (null) $\mathrm{P}$ to $\mathrm{V}$, and they consider it to be the mechanism that licenses null Ps. As mentioned in the introduction, P-to-V movement/incorporation explains the unavailability of null Ps with particle verbs.

16. A direction to look for a potential answer, given what we have said so far, is the status of place nominals in the languages that do not manifest the phenomenon. 
As explained previously, the structure of (32a) is as in (29), with 'office' occupying the position of PLACE, like 'head' occupies PLACE in (28a). In (32b), on the other hand, 'office' is a common noun, which is now the ground argument of the locative se (which contains PLACE), (28b). While 'office' moves to Spec, $\mathrm{P}_{\mathrm{Loc}}$ in (32a), 'the office' in (32b) does not.

A question that the proposal laid out so far is able to answer has to do with the facts in section 3.1, namely, the observation that null Ps are possible in fewer instances when they are locatives than when they are directional. The facts are repeated below, where it can be seen that null Ps are not accepted in (10b), but they are fine in (8b), while no similar contrast arises for directionals, (11a).

(8b) Emina ?(sto/sti) gymnastirio/sxolio/grafio/eklisia mexri arga. stayed-1s (se.the-neu/fem) gym/school/office/church until late 'I stayed at the gym/school/office/church until late.'

(10b) Sinithos troo *(sto) gymnastirio/sxolio/grafio. usually eat-1s se.the gym/school/office 'I usually eat at the gym/school/office.'

(11a) Pao/girizo (sto/sti) gymnastirio/sxolio/grafio/eklisia. go-1s/return-1s (se.the-neut/fem) home/gym/school/office/church 'I go to the gym/school/office/church.'

As mentioned in passing earlier, this difference is to be sought within the relation of the locative vs. directional PPs with the verbs that introduce them, as the former are not always their arguments. If we consider ime 'be' or meno 'stay', for instance, we can safely assume that, as verbs that denote location, they select for a locative P, hence, the PPs in (8b) are their arguments. One cannot possibly claim the same for magirevo 'cook' or troo 'eat' however - which amounts to saying that the locative PPs in (10b) are adjuncts. As a result, $\mathrm{PP}_{\mathrm{Loc}}$ cannot incorporate into the PredP in the latter case once the place nominal - the same in (8b) and (10b) - has moved into its specifier position: hence, (30) is illicit, with the result that (10b) is ungrammatical with a null $\mathrm{P}$. On the other hand, motion verbs such as pao/pigeno 'go', epistrefo/girizo 'return', (11a), select the directional goal PP that follows them (and, in turn, $\mathrm{P}_{\mathrm{Goal}}$ selects for a locative $\mathrm{PP}$ whose argument is the place nominal). As a result, $\mathrm{PP}_{\mathrm{Goal}}$ can always incorporate into PredP, once $\mathrm{PP}_{\mathrm{Loc}}$ has moved into its Specifier position, (31). ${ }^{17}$

17. Consistent with the dichotomy within the class of non-motion verbs, as defined above, is the fact that the former type are unaccusative but the latter unergative and this is directly observable in languages with auxiliary selection. In Belinzonese, for instance, there is a different auxiliary for stay, (i), than for work, (ii), associated with the fact that only in the former case is a null P possible, (iii) vs. (iv).

(i) Sum sctai in gir tüt al dì am stayed in round all the day 'I was around all day.' 
Another question that one may come up with once the above are taken under closer scrutiny is why we consider the nominals in (8) to instantiate, rather than modify, PLACE. Note that we practically consider such nominals to boil down to adverbials such as here and there, which can also be the arguments of a null locative or directional $\mathrm{P}$, although of one that is obligatorily null: ${ }^{18}$

\section{(33) Emina/piga eki. \\ stayed-1s/went-1s there \\ 'I stayed/went there.'}

Recall that, here and there are precisely the type of elements that have been considered to modify, rather than instantiate, PLACE (see Kayne 2004), an idea that is adopted by Terzi $(2008,2010)$ for their Greek counterparts. Moreover, as is illustrated in (23), a number of Greek locative Ps are considered the modifiers of PLACE, and these are locative expressions that can (also) surface without a ground argument, just as the nominals under investigation:

(34) Emine/pige piso.

stayed-3s/went-3s behind

'She stayed/went behind.'

While I do not believe it makes a whole lot of difference for the current issues at stake to consider the place nominals that surface as the complements of null Ps to instantiate, rather than modify, PLACE, I will consider the former view to them as more appropriate for two reasons: first, elements such as here/there, (35a), and the

(ii) Ho laurò tüt al dì have worked all the day 'I have worked all day.'

(Cattaneo, p.c.)

(iii) Te scte (a) ca'. cl stay at home 'You stay at home.'

(iv) Te lavura *(a) ca'. cl work at home 'You work at home.'

(Cattaneo 2009: p. 268)

18. The obligatorily null Ps in the presence of adverbial complements are accounted for easily, given what we said about the pair in (32). If an overt $\mathrm{P}$ amounts to a common noun complement, as is the case in (32b), we do not expect to encounter an overt $\mathrm{P}$ with an adverbial complement, since adverbials have no counterpart common nouns. If however (place) adverbials are like place nominals, i.e., as in (32a), a question that arises is why exo fai eki 'I have eaten there' is grammatical, while (10b) is not with a null $\mathrm{P}$. The same question arises for exo fai spiti, 'I have eaten at home'. I am afraid I have no answers to this question, except perhaps from the observation that home patterns the behaviour of locative adverbials in certain respects, in ways other place nominals do not - but the extend to which this is indeed so requires further investigation. On the other hand, the opposite question arises for Paduan in (7), since one would expect the paradigm to be grammatical with an overt spatial P, given that caza is also a common noun, i.e., 'house', in Paduan. Cattaneo (2009) suggests that this is so because caza does not have a bare counterpart in Paduan. 
locatives in $(34)=(35 b)$, can also surface as the modifiers of an overt PLACE, i.e., meros, while the place nominals under investigation cannot, $(35 \mathrm{c})$ :

(35) a. to edo/eki meros

the here/there place

b. to piso/brosta meros

the back/front place

c. *to spiti/grafio/etc. meros

the home/office/etc. place

Second, since the items that surface as the arguments of null Ps are nominals in phonetic shape, it sounds more reasonable to hold that they instantiate, rather than modify, PLACE, since the latter is also a nominal.

To sum up, we have investigated in this section the main properties of the nominal arguments of spatial Ps that surface without phonetic content, which, we believe, have contributed to a better understanding of the phenomenon of the associated null Ps. To this effect, we consider the occurrence of null spatial Ps to be related to the fact that their nominal arguments have a special status, that of place nominals. These are different from common nouns, even when identical to them in phonetic shape, in that they instantiate the (otherwise) silent noun PLACE. As such, place nominals are able to raise to the specifier position of the selecting spatial Ps and satisfy the lexicalization requirement of their Edge - essentially satisfying an EPP property of Ps. In this respect, we differ from I\&D's (2006) account of the Greek facts which does not seem to consider such nominals any different from common nouns, with which they even share an EPP property (of D). While there is no evidence for an EPP property of the Greek D (see also Lechner and Anagnostopoulou 2005), we hope we have demonstrated here that the nominal complements of null Ps are fundamentally different from common nouns (and more similar to adverbials). We thus take sides with accounts such as Collin's (2007) for English home, or Cattaneo's (2009) for similar facts in Northern Italian Dialects, on which we expand here via the data from Greek, where the presence of null Ps is much more widespread allowing us to investigate various aspects of the phenomenon. While the analysis developed does not have an answer to why not all spatial Ps have a null variant, or, why null Ps are possible in some languages but not in others, we believe we are a step closer to understanding the various sides of the phenomenon, having also identified central points that require further investigation.

\section{References}

Anagnostopoulou, E. (2003). On Double Object Alternations and Clitics. Berlin: Mouton de Gruyter.

Anagnostopoulou, E. (2005). 'Cross-linguistic and cross-categorial variation of datives.' In: Stavrou, M.; Terzi, A. (eds.). Advances in Greek Generative Syntax. Amsterdam: John Benjamins, pp. 61-126. 
Cattaneo, A. (2009). It is all about clitics: The case of a Northern Italian Dialect like Bellinzonese. Ph.D. dissertation, New York University.

Cinque, G. (2010). 'Mapping Spatial PPs: An Introduction.' In: Cinque, G.; Rizzi, L. (eds.). Mapping Spatial PPs. The Cartography of Syntactic Structures, volume 6. New York: Oxford University Press, pp. 3-25.

Collins, C. (2007). 'Home Sweet Home.' NYU Working Papers in Linguistics 1: 1-34. den Dikken, M. (1995). Particles. New York: Oxford University Press.

den Dikken, M. (2006). 'Vacuous movement in focus - On the syntax of higher-subject $w h$-questions and relative clauses. Paper presented at GLOW 29, Barcelona.

Ioannidou, A.; den Dikken, M. (2006). 'P-drop, D-drop and D-spreading.' Ms., CUNY Graduate Center.

Kayne, R. S. (2004). 'Here and There.'. In: Leclère, C.; Laporte, E.; Piot, M.; Silberztein, M. (eds.). Syntax, Lexis and Lexicon-Grammar. Papers in Honour of Maurice Gross. Amsterdam: John Benjamins, pp. 253-275. (also in Kayne 2005)

Kayne, R. S. (2005). Movement and Silence. New York: Oxford University Press.

Keyser, S. J. (1975). 'A partial history of the relative clause in English.' In: Grimshaw, J. (ed.). University of Massachusetts occasional papers in linguistics 1: Papers in the history and structure of English. Amherst: GLSA, University of Massachusetts.

Lakusta, L.; Landau, B. (2005). 'Starting at the end: the importance of goals in spatial language.' Cognition 96: 1-33.

Lechner, W.; Anagnostopoulou, E. (2005). 'Clitics and Adjacency in Greek PPs.'. In: Broekhuis, H.; Corver, N.; Huybregts, R.; Kleinhenz, U.; Koster, J. (eds.). Organizing Grammar. Linguistic Studies in Honor of Henk van Riemsdijk. Berlin: Mouton de Gruyter, pp. 390-406.

Longobardi, G. (2001). 'Formal Syntax, Diachronic Minimalism and Etymology: The History of French Chez.' Linguistic Inquiry 32: 275-302.

Nchare, L.; Terzi, A. (2010a). 'Spatial Expressions in Shupamem.' To appear in the Proceedings of the $40^{\text {th }}$ Annual Conference on African Linguistics.

Nchare, L.; Terzi, A. (2010b). 'Lexicalizing structure cross categorially.' Paper presented at the $8^{\text {th }}$ GLOW in Asia Conference, Beijing, August 2010.

Pantcheva, M. (to appear). 'The syntactic structure of locations, goals and sources.' Linguistics.

Pesetsky, D.; Torrego, E. (2001). 'T-to-C movement: Causes and consequences.' In: Kenstowitcz, M. (ed.). Ken Hale: a life in language. Cambridge, MA: MIT Press.

van Riemsdijk, H. (1978). A Case Study in Syntactic Markedness: the Binding Nature of Prepositional Phrases. Dordrecht: Foris.

Svenonius, P. (2010). 'Spatial P in English.'. In: Cinque, G.; Rizzi, L. (eds.). Mapping Spatial PPs: The Cartography of Syntactic Structures 6. New York: Oxford University Press, pp. 127-160.

Terzi, A. (2008). 'Locative Prepositions as Modifiers of an Unpronounced Noun.' Proceedings of WCCFL 26, pp. 471-480.

Terzi, A. (2010). 'Locative Prepositions and Place.' In: Cinque, G.; Rizzi, L. (eds.). Mapping Spatial PPs. The Cartography of Syntactic Structures, volume 6. New York: Oxford University Press, pp. 196-224.

Valiouli, M.; Psaltou-Joycey, A. (1994). 'Pame plateia? Hrisi I apousia tou emprothetou arthrou.' In: Proceedings of the 15th Annual Meeting of the Department of Linguistics, School of Philology, Aristotle University of Thessaloniki, pp. 292-303. 